\title{
Comparison of severe and non-severe COVID-19 pneumonia: review and meta-analysis
}

Weiping Ji, Jing Zhang, Gautam Bishnu, Xudong Du, Xinxin Chen, Hui Xu, Xiaoling Guo, Zhenzhai Cai, Xian Shen

(Team of prevention, control, diagnosis and treatment of novel coronavirus, The Second Affiliated Hospital of Wenzhou Medical University, Zhejiang, 325003, China.)

*Correspondence: Xian Shen, Team leader of prevention, control, diagnosis and treatment of novel coronavirus, The Second Affiliated Hospital of Wenzhou Medical University, Zhejiang, 325003, China. Fax: +86-577-8800-2709. E-mail: 18817350420@126.com.

Keywords: NCP, novel coronavirus, COVID-19, severe,non-severe,pneumonia

Abbreviations: NCP (novel coronavirus pneumonia), ARDS (acute respiratory distress syndrome) 


\begin{abstract}
Objective: To compare the difference between severe and non-severe COVID-19 pneumonia and figure out the potential symptoms lead to severity.
\end{abstract}

Methods: Articles from PubMed, Embase, Cochrane database, and google up-to 24 February 2020 were systematically reviewed. Eighteen Literatures were identified with cases of COVID-19 pneumonia. The extracted data includes clinical symptoms, age, gender, sample size and region et al were systematic reviewed and meta analyzed.

Results: 14 eligible studies including 1,424 patients were analyzed. Symptoms like fever (89.2\%), cough (67.2\%), fatigue (43.6\%) were common, dizziness, hemoptysis, abdominal pain and conjunctival congestion/conjunctivitis were rare. Polypnea/dyspnea in severe patients were significantly higher than non-severe $(42.7 \%$ vs. $16.3 \%$, $\mathrm{P}<0.0001)$. Fever and diarrhea were higher in severe patients $(\mathrm{p}=0.0374 \mathrm{and} 0.0267)$. Further meta-analysis showed incidence of fever(OR1.70,95\%CI 1.01-2.87), polypnea/dyspnea(OR3.53, 95\%CI 1.95-6.38) and diarrhea(OR1.80,95\%CI 1.06-3.03) was higher in severe patients, which meant the severe risk of patients with fever, polypnea/dyspnea, diarrhea were $1.70,3.53,1.80$ times higher than those with no corresponding symptoms.

Conclusions: Fever, cough and fatigue are common symptoms in COVID-19 pneumonia. Compared with non-severe patients, the symptoms as fever, polypnea/dyspnea and diarrhea are potential symptoms lead to severity.

\title{
Introduction
}

In December 2019, a series of unknown caused pneumonia appeared in Wuhan, it's clinical manifestations were very similar to viral pneumonia ${ }^{[1]}$. Later novel coronavirus was found as source virus, and named COVID-19 ${ }^{[2]}$. At present, novel coronavirus pneumonia (NCP) had been rapidly spread throughout China and overseas countries ${ }^{[3-5]}$. Human-to-human transmission of this virus was proved ${ }^{[6-7]}$. The clinical features of NCP patients were diversified, in severe cases it may lead to acute respiratory distress syndrome (ARDS) and even death ${ }^{[8-11]}$. Currently, no systematic review and Meta-analysis of the clinical characteristics of NCP was found. This paper reviewed and compared the difference between severe and non-severe of the disease, which would help to better understand and guide future.

\section{Method}

Sources and search criteria 
medRxiv preprint doi: https://doi.org/10.1101/2020.03.04.20030965; this version posted March 9, 2020. The copyright holder for this preprint

We conducted a comprehensive systematic search of PubMed, Embase, Cochrane database, and google to find all published studies that describe the clinical characteristics of COVID-19, using the search terms, "novel coronavirus", "SARS-CoV-2", "COVID-19".

According to title and abstract, two independent researchers selected and classified literatures, and reviewed all followed criteria.

Inclusion and exclusion criterina

Literatures described NCP patient's clinical signs. If there were duplicates in the study population, the literature with the largest sample size will be included. Cases that did not describe the clinical characteristics of NCP patients and repeated cases were excluded. Articles published by the same author were carefully screened to identify duplication.

Data extraction and analysis

All available publications have been carefully analyzed and strictly reviewed. The collected clinical data include population data (age, gender), number of patients and clinical manifestations. Full-text versions of relevant articles were reviewed, quality of the selected articles were evaluated, and clinical characteristics were extracted. We compared the clinical characteristics of severe and non-severe patients originally from three articles classified NCP patients as severe and non-severe.

Statistical analysis

SAS 9.4 and Review Manager 5.3 software were used for analysis and drawing.

Continuous variables were represented by median and quartile ranges (IQR).

Classification variables were summarized as counts and percentages in each category.

The age, gender, number and clinical signs of NCP patients were statistically described;

Cochran-mantel-Haenszel test (stratified chi-square test) was used to compare the differences between severe and non-severe NCP. With OR (Odds ratio) as the effect quantity, we used Mantel-Haenszel test with fixed or random effect for further meta-analysis of the clinical signs with statistical differences, and showed by drawing forest map. Symmetry tested by funnel plot.

\section{Results}

Search result

A total of 333 relevant literatures published in PubMed and other databases were detected, 68 were removed because of duplication. 265 were removed based on the inclusion criteria. 23 literaturesdid not report clinical signs. 4 were excluded because of casesoverlapped[8-9.12-13]. Finally, 14 articles were included for the final 
medRxiv preprint doi: https://doi.org/10.1101/2020.03.04.20030965; this version posted March 9, 2020. The copyright holder for this preprint

analysis[10-11.14-25]. Fig 1 shows the study selection flowchart. Data from all eligible studies were obtained frompublished manuscripts.

Synthesis of results

A systematic review showed that 610 patients $(42.8 \%)$ with NCP were female. Fever $(89.2 \%)$ and cough $(67.2 \%)$ were the most common symptoms, followed by fatigue (43.6\%), phlegm (28.6\%), shortness of breath/difficulty(21.7\%), and the less common symptoms were dizziness, hemoptysis, abdominalpain,

conjunctivalcongestion/conjunctivitis.1,377 cases were divided into severe group $(1,110)$ and non-severe group (267), Stratified chi-square test showed that there was nosignificant difference in gender between the two groups $(\mathrm{P}>0.05)$, and the median age of severe patients was slightly older. Polypnea/dyspnea in severe patients were significantly higher than in non-severe patients ( $42.7 \%$ vs.16.3\%, $\mathrm{P}<0.0001)$, fever and diarrhea were higher in severe patients $(\mathrm{P}=0.0374$ and0.0267). Conjunctival congestion/conjunctivitis ( $\mathrm{P}=0.0176)$, hemoptysis $(\mathrm{P}=0.0344)$, anorexia $(\mathrm{P}=0.0008)$, dizziness $(\mathrm{P}=0.0023)$ and abdominal pain $(\mathrm{P}=0.0015)$ may highly occurred in severe patients, but the dates of these symptoms only been reported in one or two literatures, so inter-group comparisons of these symptoms should be treated with caution. (See fig 2 and 3)

Meta analysis results

3 literatures including 262 cases in the severe group (245 fever,93.51\%) and 1,095 cases in the non-severe group (967 fever,88.31\%) were used to meta analysis for fever; Three studies were considered to be homogeneous, and fixed effect model $\left(\mathrm{Chi}^{2}=0.88, \mathrm{P}=0.64\right.$, $\left.\mathrm{I}^{2}=0 \%\right)$. The pooled effect was $1.70(95 \% \mathrm{CI}, 1.01-2.87)$ indicating fever patients had a 1.70 times higher incidence of severe risk than non-fever. On symptoms of polypnea/dyspnea, 262 cases in the severe group(112 polypnea/dyspnea,42.75\%) and 1095 cases in the non-severe group(179polypnea/dyspnea,68.32\%). Test showed that 3 literatures have certain heterogeneity $(\mathrm{Chi} 2=5.26, \mathrm{P}=0.07, \mathrm{I} 2=62 \%)$, so the random effect model was adopted; The individual OR effect showed differently, but combined OR effect was 3.53 (95\%CI, 1.95-6.38), indicating the incidence of severe risk of the patients with polypnea/dyspnea was 3.53 times higher than those none. On symptoms of diarrhea, 266 cases in the severe group (25 diarrhea,9.40\%) and 1,110 cases in the non-severe group (48diarrhea,4.32\%). Test showed homogeneity $\left(\mathrm{Chi}^{2}=0.32\right.$, $\left.\mathrm{P}=0.85, \mathrm{I}^{2}=0 \%\right)$ and fixed effect model was used, The combined OR value was 1.80 (95\%CI, 1.06-3.03), indicating the incidence of diarrhea in the severe group 
medRxiv preprint doi: https://doi.org/10.1101/2020.03.04.20030965; this version posted March 9, 2020. The copyright holder for this preprint

significantly higher than non-severe group, and the severerisk of diarrheapatients was 1.80 times higher than those none. (See Fig 4)

The graphs in funnel plots of fever, polypnea/dyspnea and diarrhea are basically symmetrical, which looks like no significant publication deviation. (See fig 5)

\section{Discussion}

There was no difference in proportion of gender between severe and non-severe NCP patients, which was consistent with the latest report[11-14]. Most of the patients showed fever and cough. Compared with non-severe patients, Fever, Polypnea/dyspnea and Diarrhea were more common in severe patients. But recent reports showed that there was no difference in the proportion of fever and diarrhea between severe and non-severe patients [10.11.14]. In addition, the symptoms of Polypnea/dyspnea were similar to those reports[10-11], but Zhang et al.[14]report had no statistical difference. One possible explanation was that in previous reports, the sample size of patients was relatively small or it came from the early epidemic phase of NCP.

NCP patients had the different clinical classification of disease severity. Non-severe $\mathrm{NCP}$ was with fever, respiratory tract symptoms, and image findings of pneumonia.

Severe NCP met diagnostic criteria[26]. This review found preliminary evidence from three literatures that fever, polypnea/dyspnea and diarrhea are statistically significant diagnostic indicators for severe NCP patients and Polypnea/dyspnea was most predictable. Clinician had to arouse great attention on diagnostic value of them in future. In the early stages of NCP nonspecific signs and symptoms may be clinically indistinguishable from other common infectious diseases, especially winter respiratory virus. These characteristics of NCP had some similarities with SARS-CoVand MERS-CoVinfections[27.28]. However, patients with COVID-19 rarely had obvious signs and symptoms of upper respiratory tract (nasal obstruction, rhinorrhea, runny nose, sore throat). In addition, intestinal signs and symptoms such as diarrhea were rare in NCP patients, while about 20-25\% of patients with MERS-CoV or SARS-CoV infection had diarrhea. It should be noted that fever of $\mathrm{NCP}(10.8 \%)$ patients was more common than SARS-CoV (1\%) and MERS-CoV(2\%)[29].

Our systematic review had limitations. Firstly, most of the data in this study are from retrospective studies and case reports, which usually report successful management and are affected by selection and publication bias. Secondly, the datacollection of some cases is incomplete. So the statistical test and the discovery of p-value should be carefully explained. Thirdly, the number of included studies is not enough, the test 
efficiency is insufficient, symmetry can be observed, but it is difficult to evaluate symmetry.

\section{Conclusion}

The common symptoms NCP patients were fever, cough and fatigue. Compared with non-severe NCP patients, the symptoms as fever, polypnea/dyspnea and diarrhea were more common in severe patients. Those were potential symptoms which might lead patients to severity.

\section{Funding}

No Funding supported the project

\section{Authors' contributions}

Weiping Ji, Jing Zhang, Hui Xu, Xiaoling Guo designed and completed the manuscript. Gautam Bishnu and Xudong Du completed data and language work, Zhenzhai Cai and Xinxin Chen completed statistics and verification, Xian Shen completed the review and revision of the paper, and guided the whole process.

\section{Acknowledgements}

The authors declared no competing interests exist.

\section{Reference}

1.WHO. Novel coronavirus - China. Jan 12, 2020. http://www.who. int/csr/don/12-january-2020-novel-coronavirus-china/en/ (accessed Jan 19, 2020).

2.Lu R, Zhao X, Li J, et al. Genomic characterization and epidemiology of 2019 novel coronavirus: implications of virus origins and receptor binding. Lancet. 2020. doi: 10.1016/S0140-6736(20)30251-8.

3.Zhu N, Zhang D, Wang W et al. A novel coronavirus from patients with Pneumonia in China, 2019. N Engl J Med. 2020. DOI: 10.1016/j.jinf.2020.02.018.

4.Lu H, Stratton CW, Tang YW, et al.Outbreak of pneumonia of unknown etiology in Wuhan China: the mystery and the miracle. J Med Virol. 2020. DOI: 10.1002/jmv.25678.

5.Bogoch II, Watts A, Thomas-BachliA et al. Potential for global spread of a novel coronavirus from China. J Travel Med. 2020. DOI: 10.1093/jtm/taaa011.

6. Li Q, Guan X, Wu P,et al. Early transmission dynamics in wuhan, china, of novel coronavirus-infected pneumonia. N Engl J Med, 2020. DOI: 10.1056/NEJMoa2001316.

7. Chan JF, Yuan S, Kok KH et al. A familial cluster of pneumonia associated with the 2019 novel coronavirus indicating person-to-person transmission: a study of a family cluster. Lancet. 2020. DOI: 10.1016/S0140-6736(20)30154-9. 
medRxiv preprint doi: https://doi.org/10.1101/2020.03.04.20030965; this version posted March 9, 2020. The copyright holder for this preprint (which was not certified by peer review) is the author/funder, who has granted medRxiv a license to display the preprint in perpetuity.

It is made available under a CC-BY-NC-ND 4.0 International license .

8.Chen N, Zhou M, Dong X et al. Epidemiological and clinical characteristics of 99 cases of 2019 novel coronavirus pneumonia in Wuhan, China: a descriptive study. Lancet. 2020. DOI: 10.1016/S0140-6736(20)30211-7.

9. Huang C, Wang Y, Li X et al. Clinical features of patients infected with 2019 novel coronavirus in Wuhan, China. Lancet. 2020. DOI: 10.1016/S0140-6736(20)30183-5.

10.Guan W, Ni Z, Hu Y et al. Clinical characteristics of 2019 novel coronavirus infection in China. medRxiv. 2020. doi: https://doi.org/10.1101/2020.02.06.20020974.

11.Wang D, Hu B, Hu C et al. Clinical Characteristics of 138 Hospitalized Patients With 2019 Novel Coronavirus-Infected Pneumonia in Wuhan, China. JAMA. 2020. DOI:

10.1001/jama.2020.1585.

12. Xiaobo Yang, Yuan Yu,Jiqian Xuet al. Clinical course and outcomes of critically ill patients with SARS-CoV-2 pneumonia in Wuhan, China: a single-centered, retrospective, observational study. Lancet Respiratory Medicine. 2020.

DOI:https://doi.org/10.1016/S2213-2600(20)30079-5.

13. Yanli Liu, Wenwu Sun, Jia Li et al. Clinical features and progression of acute respiratory 1 distress syndrome in 2 coronavirus disease 2019. medRxic.

doi: https://doi.org/10.1101/2020.02.17.20024166.

14.Zhang Jin-Jin, Dong Xiang, Cao Yi-Yuan et al. Clinical characteristics of 140 patients infected by SARS-CoV-2 in Wuhan, China. Allergy.2020. doi:10.1111/all.14238.

15.Chang De, Lin Minggui, Wei Lai et al. Epidemiologic and Clinical Characteristics of Novel Coronavirus Infections Involving 13 Patients Outside Wuhan, China. JAMA. 2020.

doi:10.1001/jama.2020.1623.

16. COVID-19 National Incident Room Surveillance Team. COVID-19, Australia: Epidemiology

Report 3 (Reporting week ending 19:00 AEDT 15 February 2020). Commun Dis Intell. 2020. doi:10.33321/cdi.2020.44.15.

17. Wei Min, Yuan Jingping, Liu Yu et al. Novel Coronavirus Infection in Hospitalized Infants Under 1 Year of Age in China. JAMA.2020. doi:10.1001/jama.2020.2131.

18.Bastola Anup., Sah Ranjit., Rodriguez-Morales Alfonso J et al. The first 2019 novel coronavirus case in Nepal. Lancet Infect Dis, 2020. doi:10.1016/S1473-3099(20)30067-0.

19.Bernard Stoecklin Sibylle,Rolland Patrick,Silue Yassoungo et al. First cases of coronavirus disease 2019 (COVID-19) in France: surveillance, investigations and control measures. Euro Surveill. 2020. DOI: 10.2807/1560-7917.ES.2020.25.6.2000094.

20.Pongpirul Wannarat A,Pongpirul Krit,Ratnarathon Anuttra C et al. Journey of a Thai Taxi Driver and Novel Coronavirus .N. Engl. J. Med. 2020. DOI: 10.1056/NEJMc2001621. 
medRxiv preprint doi: https://doi.org/10.1101/2020.03.04.20030965; this version posted March 9, 2020. The copyright holder for this preprint (which was not certified by peer review) is the author/funder, who has granted medRxiv a license to display the preprint in perpetuity.

It is made available under a CC-BY-NC-ND 4.0 International license .

21.Kim Jin Yong,Choe Pyoeng Gyun,Oh Yoonju et al. The First Case of 2019 Novel Coronavirus Pneumonia Imported into Korea from Wuhan, China: Implication for Infection Prevention and Control Measures.J. Korean Med. Sci. 2020. DOI: 10.3346/jkms.2020.35.e61.

22.Silverstein William Kyle,Stroud Lynfa,Cleghorn Graham Edward et al. First imported case of 2019 novel coronavirus in Canada, presenting as mild pneumonia. Lancet. 2020. DOI:

10.1016/S0140-6736(20)30370-6.

23.Holshue Michelle L,DeBolt Chas,Lindquist Scott et al. First Case of 2019 Novel Coronavirus in the United States.N. Engl. J. Med. 2020, DOI: 10.1056/NEJMoa2001191.

24.Liu Ying-Chu,Liao Ching-Hui,Chang Chin-Fu et al. A Locally Transmitted Case of SARS-CoV-2 Infection in Taiwan. N. Engl. J. Med. 2020, DOI: 10.1056/NEJMc2001573.

25.Phan Lan T,Nguyen Thuong V,Luong Quang C et al. Importation and Human-to-Human

Transmission of a Novel Coronavirus in Vietnam .N. Engl. J. Med. 2020, DOI:

10.1056/NEJMc2001272.

26. WHO. Clinical management of severe acute respiratory infection when novel coronavirus (nCoV) infection is suspectedInterim guidance. Jan 28, 2020.

27. Lee N, Hui D, Wu A, et al. A major outbreak of severe acute respiratory syndrome in Hong Kong. N Engl J Med. 2003; 348: 1986-94.

28. Assiri A, Al-Tawfiq JA, Al-Rabeeah AA, et al. Epidemiological, demographic, and clinical characteristics of 47 cases of Middle East respiratory syndrome coronavirus disease from Saudi Arabia: a descriptive study. Lancet Infect Dis. 2013; 13: 752-61.

29. Leung WK, To KF, Chan PK, et al. Enteric involvement of severe acute respiratory syndrome-associated coronavirus infection. Gastroenterology. 2003;125:1011-7. 


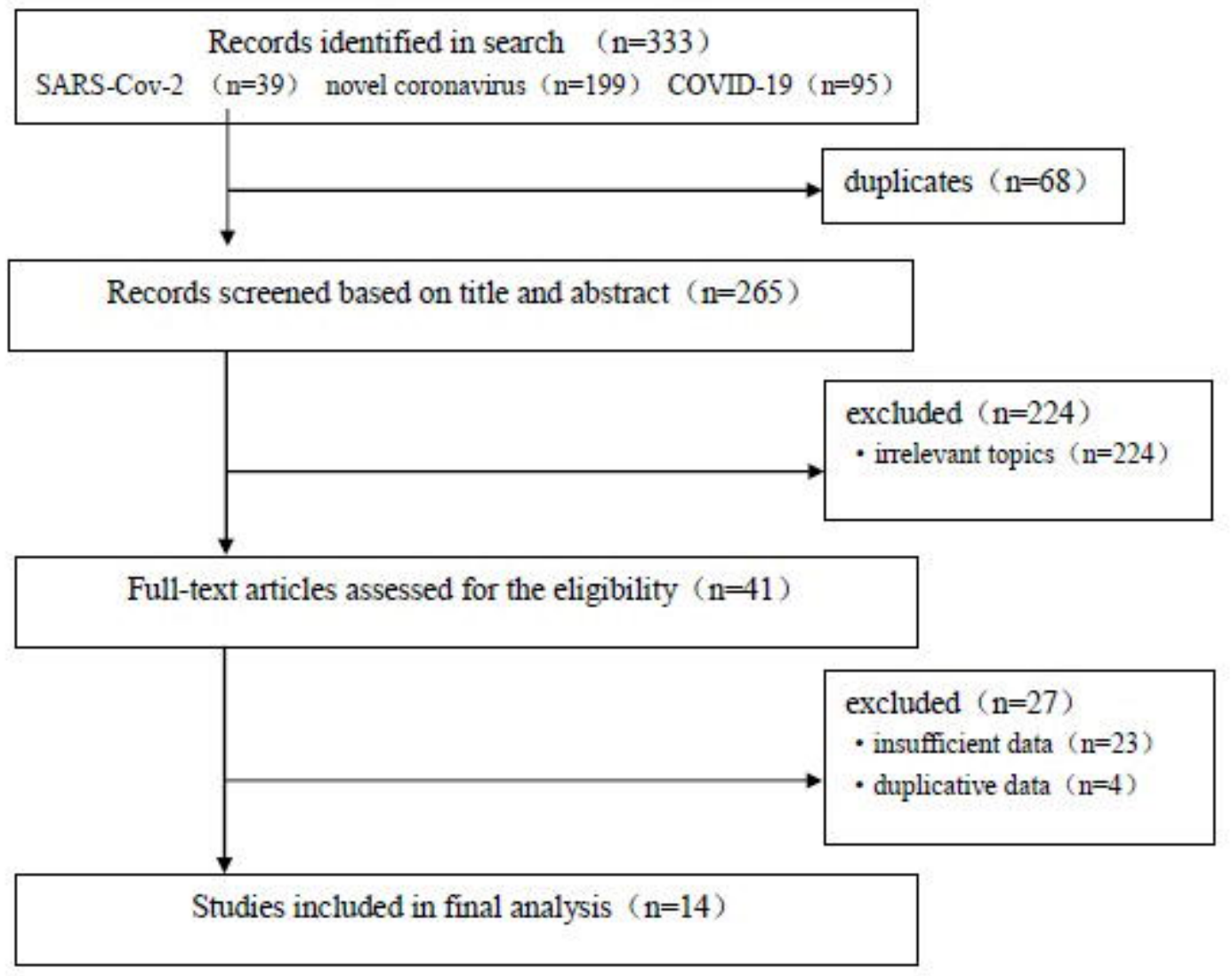

Flowchart diagram of selected studies included in this meta-analysis 
Fig 2: Clinical signs description of the patients

\begin{tabular}{|c|c|c|c|c|c|c|c|}
\hline & $\begin{array}{c}\text { Literature } 1 \\
\mathrm{~N}=1099\end{array}$ & $\begin{array}{c}\text { Literature } 2 \\
\mathrm{~N}=138\end{array}$ & $\begin{array}{c}\text { Literature } 3 \\
\mathrm{~N}=140\end{array}$ & $\begin{array}{l}\text { Literature } 4 \\
\qquad N=13\end{array}$ & $\begin{array}{l}\text { Literature } 5 \\
\qquad \mathrm{~N}=15\end{array}$ & $\begin{array}{c}\text { Case reports } \\
\text { summary } \\
\mathrm{N}=19\end{array}$ & $\begin{array}{c}\text { Total } \\
N=1424\end{array}$ \\
\hline Age, median(IQR or range) & $47.0(35.0-58.0)$ & $56(42-68)$ & $57(25-87)$ & $34(34-48)$ & $43(8-66)$ & $31(1-49)$ & - \\
\hline Gender, $n(\%)$ & $459(41.8)$ & $63(45.7)$ & $69 / 140(49.3)$ & $3(23.1)$ & $6(40.0)$ & $10(52.6)$ & $610(42.8)$ \\
\hline Fever, $\mathrm{n}(\%)$ & $966(87.9)$ & $136(98.6)$ & $110 / 120(91.7)$ & $12(92.3)$ & $14(93.3)$ & $15(78.9)$ & $1253(89.2)$ \\
\hline Cough, $n(\%)$ & $744(67.7)$ & $82(59.4)$ & $90 / 120(75.0)$ & $6(46.2 \%)$ & $11(73.3)$ & $11(57.9)$ & $944(67.2)$ \\
\hline Sore throat, $\mathrm{n}(\%)$ & $153(13.9)$ & $24(17.4)$ & - & - & $7(46.7)$ & $3(15.8)$ & $187(13.1)$ \\
\hline Sputum, $n(\%)$ & $367(33.4)$ & $37(26.8)$ & - & $2(15.4)$ & - & $1(5.3)$ & $407(28.6)$ \\
\hline Fatigue, $n(\%)$ & $419(38.1)$ & $96(69.6)$ & $90 / 120(75.0)$ & - & $4(26.7)$ & $3(15.8)$ & $612(43.6)$ \\
\hline Polypnea/dyspnea, $n(\%)$ & $204(18.6)$ & $43(31.2)$ & $44 / 120(36.7)$ & $8(61.5)$ & $1(6.7)$ & $5(26.3)$ & $305(21.7)$ \\
\hline Nausea/vomiting, $\mathrm{n}(\%)$ & $55(5.0)$ & $14(10.1)$ & $24 / 139(17.3)$ & - & $1(6.7)$ & $2(10.5)$ & $96(6.7)$ \\
\hline Diarrhea, $n(\%)$ & $41(3.7)$ & $14(10.1)$ & $18 / 139(12.9)$ & $1(7.7)$ & $5(33.3)$ & $3(15.8)$ & $82(5.8)$ \\
\hline Muscle/joint pain, $\mathrm{n}(\%)$ & $163(14.8)$ & $48(34.8)$ & - & $3(23.1)$ & $2(13.3)$ & $4(21.1)$ & $220(15.4)$ \\
\hline Chilly, $n(\%)$ & $125(11.4)$ & - & - & - & - & $3(15.8)$ & $128(9.0)$ \\
\hline Headache, $n(\%)$ & $150(13.6)$ & $9(6.5)$ & - & $3(23.1)$ & $3(20.0)$ & $1(5.3)$ & $166(11.7)$ \\
\hline $\begin{array}{l}\text { Nasal discomfort } \\
\text { (congestion, overflow, } \\
\text { runny), } n(\%)\end{array}$ & $53(4.8)$ & - & - & $1(7.7)$ & $5(33.3)$ & $6(31.6)$ & $64(4.5)$ \\
\hline Conjunctival & & & & & & & \\
\hline $\begin{array}{l}\text { congestion/conjunctivitis, } \\
\mathrm{n}(\%)\end{array}$ & $9(0.8)$ & - & - & - & - & $1(5.3)$ & $10(0.7)$ \\
\hline Hemoptysis, $n(\%)$ & $10(0.9)$ & - & - & - & - & $1(5.3)$ & $11(0.8)$ \\
\hline Apocleisis, $n(\%)$ & - & $55(39.9)$ & $17 / 139(12.2)$ & - & - & - & $72(5.1)$ \\
\hline Dizzy, $n(\%)$ & - & $13(9.4)$ & - & - & - & - & $13(0.9)$ \\
\hline Abdominal pain, $n(\%)$ & - & $3(2.2)$ & $8 / 139(5.8)$ & - & - & - & $11(0.8)$ \\
\hline
\end{tabular}

Note: if a certain clinical sign was not reported in a certain literature, 0 cases were treated as occurred. Literature 3 clearly pointed out that the data of signs of 140 patients were not all collected, and the calculation was based on the actual sample size. 
Fig 3: Comparison between severe and non-severe patients

\begin{tabular}{|c|c|c|c|c|c|c|c|c|c|}
\hline & \multicolumn{2}{|c|}{ Literature 1} & \multicolumn{2}{|c|}{ Literature 2} & \multicolumn{2}{|c|}{ Literature 3} & \multicolumn{2}{|c|}{ Total } & \multirow[b]{2}{*}{$P$ value } \\
\hline & $\begin{array}{c}\text { Non-severe } \\
(\mathrm{N}=926)\end{array}$ & $\begin{array}{c}\text { Severe } \\
(\mathrm{N}=173)\end{array}$ & $\begin{array}{c}\text { Non-severe } \\
(\mathrm{N}=102)\end{array}$ & $\begin{array}{l}\text { Severe } \\
(\mathrm{N}=36)\end{array}$ & $\begin{array}{c}\text { Non-severe } \\
(\mathrm{N}=82)\end{array}$ & $\begin{array}{l}\text { Severe } \\
(\mathrm{N}=58)\end{array}$ & $\begin{array}{r}\text { Non-severe } \\
(\mathrm{N}=1110)\end{array}$ & $\begin{array}{l}\text { Severe } \\
(\mathrm{N}=267)\end{array}$ & \\
\hline Age, median(IQR or range) & $\begin{array}{c}45.0(34.0- \\
57.0)\end{array}$ & $\begin{array}{c}52.0(40.0- \\
65.0)\end{array}$ & $51(37-62)$ & $66(57-78)$ & $51.5(26-78)$ & $64(25-87)$ & - & - & - \\
\hline Gender, $n(\%)$ & $386(41.7)$ & $73(42.2)$ & $49(48.0)$ & $14(38.9)$ & $44 / 82(53.7)$ & $25 / 58(43.1)$ & $479 / 1110(43.2)$ & $112 / 267(41.9)$ & 0.4588 \\
\hline Fever, $n(\%)$ & $808(87.3)$ & $158(91.3)$ & $100(98.0)$ & $36(100)$ & $59 / 67(88.1)$ & $51 / 53(96.2)$ & $967 / 1095(88.3)$ & $245 / 262(93.5)$ & 0.0374 \\
\hline Cough, $n(\%)$ & $622(67.2)$ & $122(70.5)$ & $61(59.8)$ & $21(58.3)$ & $45 / 67(67.2)$ & $45 / 53(84.9)$ & $728 / 1095(66.5)$ & $188 / 262(71.8)$ & 0.1418 \\
\hline Sore throat, $n(\%)$ & $130(14.0)$ & $23(13.3)$ & $12(11.8)$ & $12(33.3)$ & & & $142 / 1110(12.8)$ & $35 / 267(13.1)$ & 0.3136 \\
\hline Sputum, $n(\%)$ & $306(33.0)$ & $61(35.3)$ & $29(28.4)$ & $8(22.2)$ & & & $335 / 1110(30.2)$ & $69 / 267(25.8)$ & 0.7974 \\
\hline Fatigue, $n(\%)$ & $350(37.8)$ & $69(39.9)$ & $67(65.7)$ & $29(80.6)$ & $51 / 67(76.1)$ & $39 / 53(73.6)$ & $468 / 1095(42.7)$ & $137 / 262(52.3)$ & 0.3552 \\
\hline Polypnea/dyspnea, $n(\%)$ & $139(15.0)$ & $65(37.6)$ & $20(19.6)$ & $23(63.9)$ & $20 / 67(29.9)$ & $24 / 53(45.3)$ & $179 / 1095(16.3)$ & $112 / 262(42.7)$ & $<0.0001$ \\
\hline Nausea/vomiting, $n(\%)$ & $43(4.6)$ & $12(6.9)$ & $10(9.8)$ & $4(11.1)$ & $19 / 82(23.2)$ & $5 / 57(8.8)$ & $72 / 1110(6.5)$ & $21 / 266(7.9)$ & 0.7600 \\
\hline Diarrhea, $n(\%)$ & $31(3.3)$ & $10(5.8)$ & $8(7.8)$ & $6(16.7)$ & $9 / 82(11.0)$ & $9 / 57(15.8)$ & $48 / 1110(4.3)$ & $25 / 266(9.4)$ & 0.0267 \\
\hline Muscle/joint pain, $n(\%)$ & $133(14.4)$ & $30(17.3)$ & $36(35.3)$ & $12(33.3)$ & - & - & $169 / 1110(15.2)$ & $42 / 267(15.7)$ & 0.4404 \\
\hline Chilly, $\mathrm{n}(\%)$ & $99(10.7)$ & $26(15.0)$ & - & - & - & - & $99 / 1110(8.9)$ & $26 / 267(9.7)$ & 0.0992 \\
\hline Headache, $n(\%)$ & $124(13.4)$ & $26(15.0)$ & $6(5.9)$ & $3(8.3)$ & - & - & $130 / 1110(11.7)$ & $29 / 267(10.9)$ & 0.4836 \\
\hline $\begin{array}{l}\text { Nasal discomfort } \\
\text { (congestion, overflow, } \\
\text { runny), } \mathrm{n}(\%)\end{array}$ & $47(5.1)$ & $6(3.5)$ & - & - & - & - & $47 / 1110(4.2)$ & $6 / 267(2.2)$ & 0.3652 \\
\hline Conjunctival & & & & & & & & & \\
\hline $\begin{array}{l}\text { congestion/conjunctivitis, } \\
n(\%)\end{array}$ & $5(0.5)$ & $4(2.3)$ & - & - & - & - & $5 / 1110(0.5)$ & $4 / 267(1.5)$ & 0.0176 \\
\hline Hemoptysis, $n(\%)$ & $6(0.6)$ & $4(2.3)$ & - & - & - & - & $6 / 1110(0.5)$ & $4 / 267(1.5)$ & 0.0344 \\
\hline Apocleisis, $\mathrm{n}(\%)$ & - & - & $31(30.4)$ & $24(66.7)$ & $9 / 82(11.0)$ & $8 / 57(14.0)$ & $40 / 1110(3.6)$ & $32 / 266(12.0)$ & 0.0008 \\
\hline Dizzy, n(\%) & - & - & $5(4.9)$ & $8(22.2)$ & & & $5 / 1110(0.5)$ & $8 / 267(3.0)$ & 0.0023 \\
\hline Abdominal pain, $n(\%)$ & - & - & $0(0)$ & $3(8.3)$ & $2 / 82(2.4)$ & $6 / 57(10.5)$ & $2 / 1110(0.2)$ & $9 / 266(3.4)$ & 0.0015 \\
\hline
\end{tabular}

Note: Conjunctival congestion/conjunctivitis, hemoptysis, anorexia, dizziness, abdominal pain et al are only seen in some literatures. It was assumed that these symptoms did not occur in patients in other literatures during the analysis. 
Study or Subgroup Weight M-H. Fixed. $95 \% \mathrm{Cl}$

Article 1

Article 2

$89.1 \%$

$1.54[0.88 .2 .70]$

Article 3

Total $(95 \% \mathrm{Cl})$

$2.9 \%$

$1.82[0.09,38.73]$

$7.9 \%$

$3.46[0.70,17.03]$

$100.0 \% \quad 1.70[1.01,2.87]$

Heterogeneity: $\mathrm{Chi}^{2}=0.88, \mathrm{df}=2(\mathrm{P}=0.64) ; \mathrm{I}^{2}=0 \%$ M-H. Fixed. $95 \% \mathrm{Cl}$

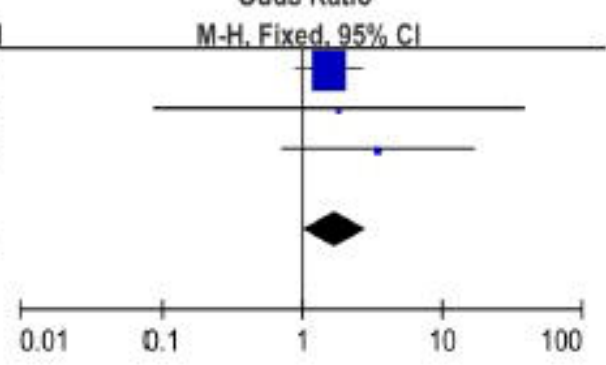

\section{Forest plot of Fever}

Odds Ratio

Study or Subgroup Weight M.H. Random. $95 \% \mathrm{Cl}$

Article 1

Article 2

Article 3

Total $(95 \% \mathrm{Cl})$

Heterogeneity: $\operatorname{Tau}^{2}=0.17 ; \mathrm{Ch}^{2}=5.26, \mathrm{df}=2(\mathrm{P}=0.07) ; \mathrm{R}^{2}=62 \%$

\section{$45.1 \%$}

$26.0 \%$

$28.9 \%$

$100.0 \%$

$3.53[1.95,6.38]$

$7.25[3.14,16.76]$

$1.94[0,92,4.13]$

Odds Ratio

M.H. Random. $95 \% \mathrm{Cl}$

Forest plot of Polypnea/dyspnea

Odds Ratio

Study or Subgroup Weight M-H.Fixed. $95 \% \mathrm{Cl}$

$\begin{array}{lll}\text { Article 1 } & 48.7 \% & 1.77[0.85,3.68] \\ \text { Article 2 } & 18.4 \% & 2.35[0.75,7.31] \\ \text { Article 3 } & 32.9 \% & 1.52[0.56,4.11]\end{array}$

Total $(95 \% \mathrm{CI}) \quad 100.0 \% \quad 1.80[1.06,3.03]$

Heterogeneity: $\mathrm{Chi}^{2}=0.32, \mathrm{df}=2(\mathrm{P}=0.85) ; \mathrm{I}^{2}=0 \%$
Odds Ratio M.H. Fixed, $95 \% \mathrm{Cl}$

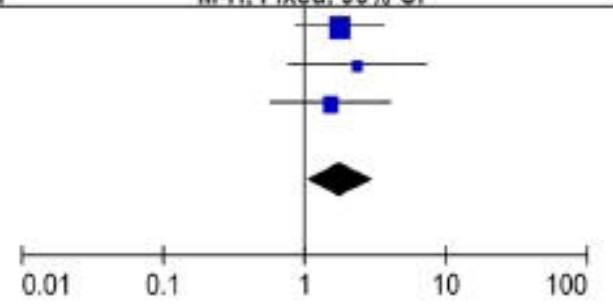


Fig 5

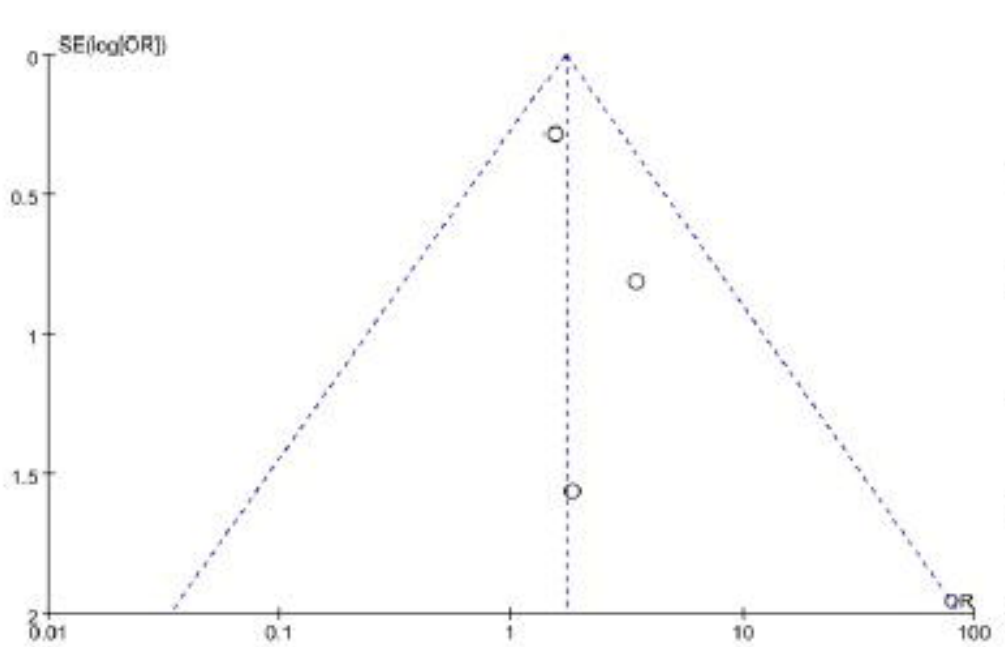

Funnel plot of Fever

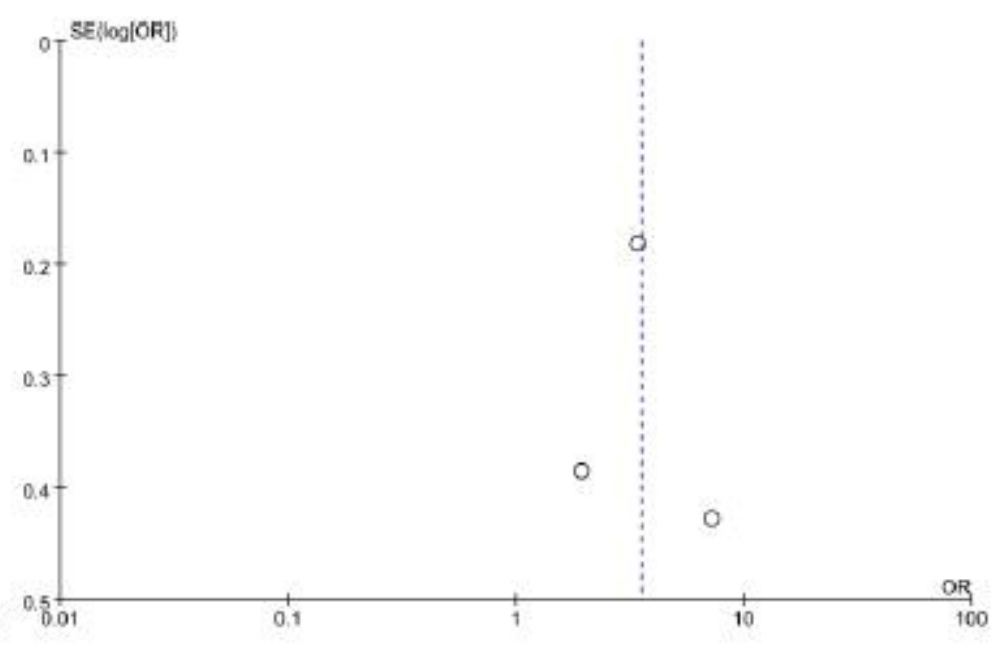

Funnel plot of Polypnea/dyspnea

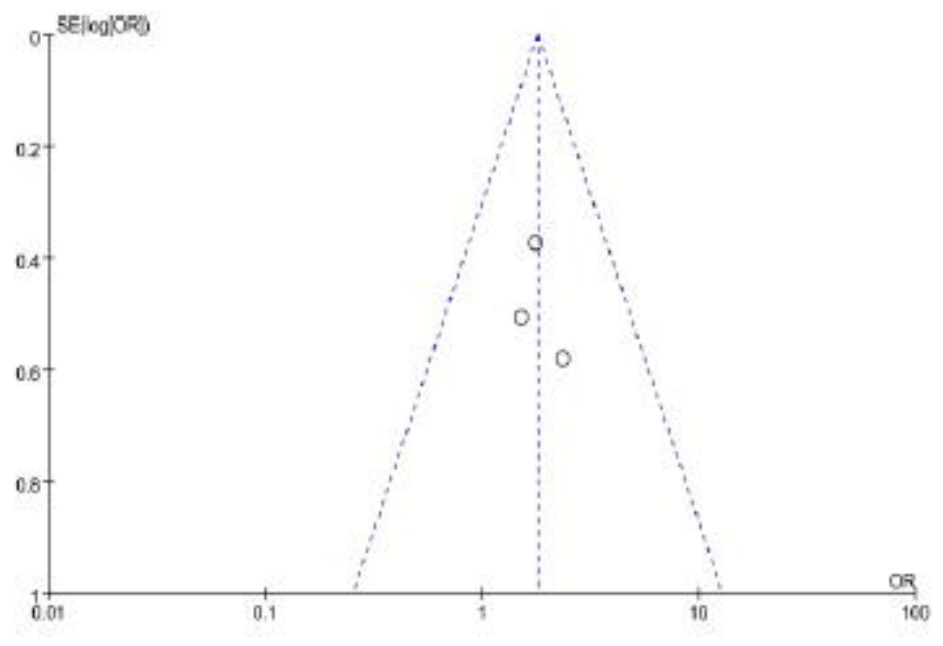

Funnel plot of Diarrhea 
medRxiv preprint doi: https://doi.org/10.1101/2020.03.04.20030965; this version posted March 9, 2020. The copyright holder for this preprint (which was not certified by peer review) is the author/funder, who has granted medRxiv a license to display the preprint in perpetuity.

It is made available under a CC-BY-NC-ND 4.0 International license .

Figure 1 legend: After selection, 5 papers of group research and 9 articles of case report were eligible, with a total of 1,424 cases. 3 papers with a total of 1,377 cases reported clinical signs of severe and non-severe patients subgroups (literature 2 was divided into ICU and non-ICU, which were assumed equivalent to severe and non-severe).

Figure 2 legend: Fever, cough, polypnea/dyspnea and diarrhea were the most common clinical signs reported in the literature, while some other signs were more or less unreported. It assumed that if a certain clinical sign was not reported in a certain literature, it would be treated as none.

Figure 3 legend: The comparison of clinical signs between severe and non-severe patients was shown among 1,377 cases, including 1,110 cases of non-severe patients and 267 cases of severe patients. Polypnea/dyspnea, fever and diarrhea showed significantly difference in two groups. In severe patients, conjunctival congestion/conjunctivitis, hemoptysis, anorexia, dizzinessand abdominal pain were more likely to occur, but because some data was incomplete, the results needed to be caution.

Figure 4 legend: Further meta-analysis was performed for fever, polypnea/dyspnea, and diarrhea. Effect value OR analysis indicated severe risk of febrile, polypnea/dyspnea and diarrhea patients were 1.70 (95\%CI, 1.01-2.87) , 3.53 (95\%CI, 1.95-6.38), 1.80 (95\% CI, 1.06-3.03) times higher than those none.

Figure 5 legend: The graphs in funnel plots of fever, polypnea/dyspnea and diarrhea are basically symmetrical, which preliminary indicates no significant publication deviation. 